Résumés des conférences et travaux

\title{
Georges Le Rider (1928-2014)
}

François de Callatay

\section{OpenEdition \\ Journals}

Édition électronique

URL : https://journals.openedition.org/ashp/1670

DOI : $10.4000 /$ ashp. 1670

ISSN : 1969-6310

Éditeur

Publications de l'École Pratique des Hautes Études

\section{Édition imprimée}

Date de publication : 1 septembre 2015

Pagination: $x x v i-x x x$

ISSN : 0766-0677

Référence électronique

François de Callatay, "Georges Le Rider (1928-2014) ", Annuaire de l'École pratique des hautes études (EPHE), Section des sciences historiques et philologiques [En ligne], 146 | 2015, mis en ligne le 28 septembre 2015, consulté le 07 juillet 2021. URL : http://journals.openedition.org/ashp/1670 ; DOI : https://doi.org/10.4000/ashp.1670 


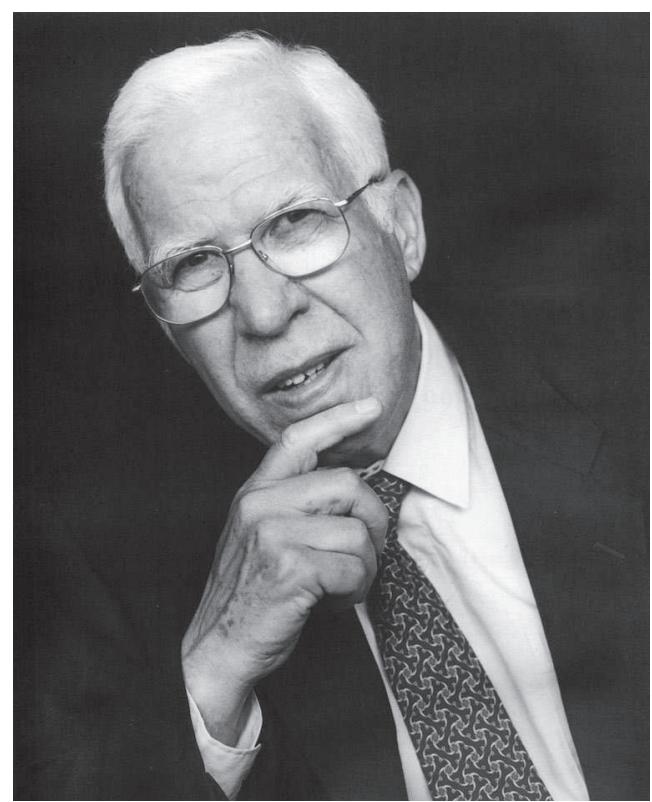

\section{GEORGES LE RIDER} (1928-2014)

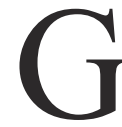

EORGES LE Rider s'est éteint chez lui le 3 juillet 2014 à Givors, près de Lyon, où il était venu passer les dernières années de sa vie. Qui contemple aujourd'hui cette vie dans toute son étendue ne peut manquer d'être frappé tant par les tragédies qui en auront marqué le début et la fin que par le chemin très lumineux et glorieux qui en aura caractérisé l'essentiel du déroulement. Une existence en forme de parabole donc qui aura vu ce pupille de la nation gravir une à une toutes les marches du système éducatif, universitaire et académique français et bâtir une œuvre construite autour des finances monétaires du monde grec qui a profondément marqué son époque ${ }^{1}$.

Georges Le Rider est né le 27 janvier 1928 dans le sud du Finistère, de deux parents instituteurs. Directeur de l'école du village, son père devait décéder un mois et demi après sa naissance, des suites des blessures contractées lors de la Première Guerre. Sa mère, qui s'était établie ensuite avec ses enfants dans le hameau de Meneham, à

1. Un important florilège de ses articles a été réédité en 1999 : Georges Le Rider, Études d'histoire monétaire et financière du monde grec. Écrits 1958-1998, Athènes, 3 vol., 1443 p. (éd. par E. Papaefthymiou, F. de Callataÿ et F. Queyrel), avec une bibliographie établie jusqu'en 1999 (p. 15-23). On trouvera une bibliographie thématique, allant elle aussi jusqu'en 1999, dans M. Amandry, «Travaux de numismatique de Georges Le Rider (1956-1999)», dans M. Amandry et S. Hurter (éd.), Travaux de numismatique grecque offerts à Georges Le Rider, Londres, 1999, p. 441-447. 
flanc de falaise, sur l'océan, ne devait pas beaucoup lui survivre. Orphelin de ses deux parents, en 1937, à l'âge de neuf ans, Georges Le Rider fut recueilli par ses oncles et tantes qui l'inscrivirent au lycée La Tour d'Auvergne de Quimper. Le déclenchement de la Seconde Guerre et l'occupation eut pour lui une conséquence inattendue. Les autorités allemandes ayant fermé les établissements scolaires de Brest, base stratégique, on avait décidé de regrouper les professeurs agrégés à Quimper, au lycée La Tour d'Auvergne précisément. Parmi ces professeurs de premier plan figurait AugustePierre Segalen, qui allait orienter d'une façon décisive la vie de Georges Le Rider. C'est ce professeur qui, repérant ses aptitudes hors-normes, en particulier s'agissant des thèmes latin et grec, évoqua devant ses yeux éblouis l'existence de l'École française d'Athènes et la voie à suivre pour y parvenir.

Georges Le Rider allait incarner l'idéal méritocratique de l'école républicaine et passer brillamment tous les concours, toutes les étapes d'un système académique exigeant et fortement balisé. Arrivé en octobre 1945 dans un Paris à peine libéré, le voilà interne au lycée Louis-le-Grand, dormant dans des chambrées de soixante-quatre avec réveil à six heures du matin. Snobés au départ par les Parisiens, les provinciaux étaient durs à la tâche et beaucoup tentaient avec succès le concours de l'ENA. Pour sa part, Georges Le Rider, champion de sa promotion en thème grec, continua la route tracée par son professeur de lycée et entra en 1948 à l'École normale supérieure. Parmi les cours choisis figurait celui de Charles Picard qui, cette année-là, avait orienté son enseignement sur la numismatique en commentant la publication récente d'Oscar Ravel sur les poulains de Corinthe. Et c'est ainsi que Georges Le Rider devint numismate en annonçant son intention de faire une étude basée sur les monnaies. Par l'entremise de Fernand Chapouthier, alors directeur-adjoint de l'École normale supérieure, un rendez-vous fut bientôt organisé avec Henri Seyrig, incontestablement la rencontre la plus marquante de sa vie professionnelle. Car Seyrig lui traça une feuille de route très claire : devenir agrégé de lettres classiques et réussir le concours d'entrée à Athènes, ce qu'il fit en 1952; profiter de son séjour athénien pour découvrir tous les chefs-d'œuvre dont il avait été nourri, et puis le rejoindre à l'Institut français d'archéologie de Beyrouth.

Georges Le Rider arriva à Athènes en mars 1953, après trois mois enchanteurs à visiter l'Italie comme c'était la coutume en ce temps-là. Accueilli par Georges Daux, il jeta son dévolu d'abord sur le monnayage de Thasos où Lily Kahil venait de découvrir un trésor de monnaies de bronze, puis - à l'instigation de Louis Robert - sur les séries crétoises qui allaient former la matière de sa thèse complémentaire : Monnaies crétoises $d u V^{e}$ au I ${ }^{e r}$ siècle $a v . J .-C$. (Paris, 1966). Il fréquenta aussi intensément le Musée numismatique d'Athènes où il se lia d'une indéfectible amitié avec Mando Oeconomidès. Mais, répondant au vœu exprimé des années plus tôt par Henri Seyrig, Georges Le Rider quitta l'École française d'Athènes, sans trop de regret à vrai dire, pour rejoindre à l'automne 1955 l'Institut français d'archéologie de Beyrouth. En pleine complicité avec Seyrig pour mentor, nouant des amitiés durables, Georges Le Rider passa là de son propre aveu des années qui furent peut-être les plus belles de sa vie. Il lança sa grande thèse sur Suse sous les Séleucides et les Parthes, les trouvailles monétaires et l'histoire de la ville (Paris, 1965) et précisa le cadre général de l'œuvre qu'il allait bâtir : l'histoire des royaumes hellénistiques expliquée par leurs monnaies. 
La guerre civile éclata à la fin mars 1958. Une place s'offrait au Cabinet des médailles de la Bibliothèque nationale. Georges Le Rider la saisit et commença alors cette carrière de vingt-trois ans passés au service du plus grand vaisseau culturel de l'État, dont quatorze à diriger le Cabinet des médailles où il avait succédé à 33 ans, en 1961, à Jean Babelon, et six à diriger le navire, comme administrateur général de 1975 à 1981. Au Cabinet des médailles, il enrichit considérablement les collections, notamment les séries grecques via l'acquisition des collections Delepierre et Seyrig, mena à bien sa grande étude sur Le monnayage d'argent et d'or de Philippe II frappé en Macédoine de 359 à 294 (Paris, 1977) et rénova le musée. À la tête de la Bibliothèque nationale, il introduisit le mécénat d'entreprise et lança des actions concertées de recherche sur le patrimoine de l'établissement, réunissant les conservateurs aux chercheurs du C.N.R.S. et aux professeurs des universités, créant au passage un conseil scientifique, organe dont l'institution était étrangement dépourvue jusque là.

Parallèlement, dès 1964 et pendant plus de trente ans, il enseigna la numismatique grecque chez nous, à la IV e section de l'École pratique des hautes études, où il avait pour partie succédé à Louis Robert, sur le bienveillant conseil d'Henri Seyrig. C'est dans l'Annuaire de l'E.P.H.E. que se trouve le résumé de ses leçons sur le monnayage d'Alexandre le Grand où l'on perçoit toute la finesse de sa pensée. Plusieurs ont décrit comment Georges Le Rider emmenait chaque lundi ses auditeurs, dont beaucoup l'on suivi plusieurs décennies durant, au sein des forges de sa propre création comme le professe les statuts de l'E.PH.E. et donnait à voir ce mélange si caractéristique d'exigence, de simplicité et de courtoisie. Comme l'a écrit Pierre Ducrey, son charme réside dans la modestie et la simplicité dépouillée des solutions qu'il propose ${ }^{1}$. Dans une langue dont il faut souligner la clarté, Georges Le Rider offre constamment à ses lecteurs l'exemple de la meilleure histoire qui se puisse écrire : celle qui, partant de tous les faits disponibles, amène au plus haut degré d'interprétation raisonnable, sans leur faire violence et sans jamais se départir de cet esprit de prudence qui caractérise l'ensemble de son œuvre.

Rendu à ses études après le lourd passage à la direction de la Bibliothèque nationale, Georges Le Rider offre l'exemple encourageant d'un savant dont le meilleur de la production scientifique aura été écrit passé la soixantaine. Nommé directeur de l'Institut français d'études anatoliennes à Istanbul en 1981, puis professeur à Paris-IV en 1984, il va multiplier les publications et les avancées scientifiques. Après la parution du grand trésor hellénistique de Meydanc1kkale découvert en 1980 près de Gülnar (Paris, 1988), Georges Le Rider se tourne de plus en plus vers les travaux de synthèse. Il revient sur ce que l'on peut dire du monnayage au nom de Philippe II (Monnayages et finances de Philippe II, un état de la question, 1996), fait une incursion dans l'Égypte lagide (Prix du blé et numéraire en Égypte lagide de 305 à 173, 1997) et surtout se concentre sur ses chers Séleucides en s'attaquant au cœur de la production monétaire, à savoir les ateliers de Séleucie du Tigre et d'Antioche (Séleucie du Tigre, les monnaies séleucides et parthes, 1998 et Antioche de Syrie sous les Séleucides : corpus des monnaies d'or et d'argent. I, De Séleucos à Antiochos V, c. 300-161, 1999).

1. P. Ducrey, «Allocution », dans Remise à Georges Le Rider de son épée d'académicien, Paris, 1990, p. 19. 
Devenu membre de l'Académie des inscriptions et belles-lettres en 1989, il est nommé professeur au Collège de France en 1993 (leçon inaugurale prononcée le 9 mars 1994) sur une chaire créée pour lui d'histoire économique et monétaire de l'Orient hellénistique, achevant une ascension académique dont son bon maître Segalen put être le témoin émerveillé presque jusqu'au bout. Les années du Collège seront, pour celui qui est alors et depuis longtemps reconnu comme le spécialiste incontesté des monnayages royaux hellénistiques, l'occasion de ramasser sa pensée et de faire connaître une trilogie embrassant l'ensemble du phénomène monétaire en Grèce ancienne, de sa naissance jusqu'à la fin des grandes monarchies hellénistiques. Il publiera ainsi avec ponctualité : La naissance de la monnaie : pratiques monétaires de l'Orient ancien, 2001 ; Alexandre Le Grand : monnaie, finances et politique, 2003 et Les Séleucides et les Ptolémées : l'héritage monétaire et financier d'Alexandre le Grand, 2006).

Les trophées accumulés en France, Georges Le Rider les avait aussi obtenus dans sa discipline à un âge précoce, presque record, à l'étranger. Dès la quarantaine, il avait été fait lauréat des deux récompenses qui passent pour les plus importantes dans le monde de la numismatique, à savoir la Archer M. Huntington Medal de l'American Numismatic Society (1968) et la médaille de la Royal Numismatic Society anglaise (1974). Mieux même, il avait aussi été élu à la présidence de la Commission internationale de numismatique, dont il dirigea les travaux de 1973 à 1979. À quoi viennent s'ajouter toute une panoplie de distinctions. Ainsi, en Belgique, il avait été fait membre d'honneur de la Société royale de numismatique de Belgique en 1970, docteur honoris causa de l'Université catholique de Louvain en 1976 et élu membre associé de l'Académie royale de Belgique en 2000.

Les recherches de Georges Le Rider ont profondément renouvelé nos connaissances du phénomène monétaire en Grèce ancienne. En particulier, il est celui qui aura le plus insisté sur la raison fiscale ${ }^{1}$ et le pragmatisme qui gouvernaient alors les affaires d'argent. Loin des constructions subtiles autant que fragiles basées sur telle allusion iconographique ou tel rapport métrologique remarquable, le monde qu'il décrit est celui de cités et de rois qui tirèrent un profit de la frappe monétaire mais ne frappèrent que lorsqu'ils en eurent besoin. Dans le grand débat (contemporain de son œuvre) sur l'économie antique, sa voix fut celle d'un moderniste qui fit valoir l'importance des choix rationnels de nature économique. Très attentif aux questions de fiduciarité et de taxation, il professait en privé un faible pour le système ouvert et souple des Séleucides par rapport aux contraintes imposées par les Ptolémées.

Ce que Henry Seyrig fut pour Georges Le Rider, un maître exigeant et un père affectueux, Georges Le Rider le fut pour moi. J'ai dit ailleurs, lors de l'eulogie prononcée à l'Académie royale de Belgique, l'ampleur de ma dette tant professionnelle qu'intellectuelle à son égard. Pour ceux qui ont eu la chance de bien le connaître, Georges Le Rider restera comme un exemple lumineux d'excellence, de sagesse et de

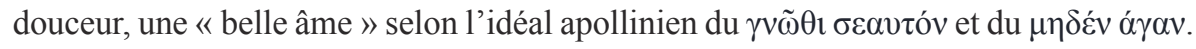

François dE CALlata $\ddot{Y}$

1. Voir F. de Callataÿ, «Fiscalité et monnayage dans l'œuvre de Georges Le Rider », dans M. Amandry et S. Hurter (éd.), Travaux de numismatique grecque offerts à Georges Le Rider, Londres, 1999, p. 109-121. 
Liste des derniers travaux

(non repris dans la bibliographie donnée en 1999 - voir note 1)

"Antimène de Rhodes à Babylone », Bulletin of the Asia Institute, n. s. 12 (Alexander's legacy in the East. Studies in honor of Paul Bernard), 1998, p. 121-140.

«Sur un passage du papyrus de Zénon $59021 »$, dans J.-Y. Empereur (éd.), Commerce et artisanat dans l'Alexandrie hellénistique et romaine. Actes du colloque d'Athènes, 11-12 décembre 1988, Athènes, 1998 (BCH suppl. 33), p. 403-407.

Antioche de Syrie sous les Séleucides. Corpus des monnaies d'or et d'argent, I. De Séleucos I à Antiochos V, c. 300-161, Paris, Académie des inscriptions et belleslettres, 1999 (Mémoire de l'Académie des inscriptions et belles-lettres, n. s. 19), 260 p. et $27 \mathrm{pl}$.

«Le monnayage d'or et d'argent frappé en Égypte sous Alexandre : le rôle monétaire d'Alexandrie ", dans J. Leclant (éd.), Alexandrie : une mégapole cosmopolite. Actes du $9^{e}$ colloque de la Villa Kérylos à Beaulieu-sur-Mer les 2 \& 3 octobre 1998, Paris, 1999, p. 11-23.

" Philippe II de Macédoine jugé par Théopompe », Numismatica e Antichità Classiche, 30, 2001, p. 87-99.

«Un essai de réforme monétaire sous Antiochos IV en 173/2? Remarques sur l'idée d'une pénurie d'argent dans les Etats hellénistiques au $\mathrm{II}^{\mathrm{e}}$ siècle », dans R. FreiStolba et K. Gex (éd.), Recherches récentes sur le monde hellénistique. Actes du colloque international organisé à l'occasion du $60^{\circ}$ anniversaire de Pierre Ducrey (Lausanne, 20-21 novembre 1998), Berne, 2001, p. 269-280.

La Naissance de la monnaie : pratiques monétaires de l'Orient ancien, Paris, PUF, 2001, XIV + $286 \mathrm{p}$.

Alexandre le Grand. Monnaie, finance et politique, Paris, PUF, 2003, XI +363 p. (trad. anglaise : Alexander the Great. Coinage, Finances, and Policy, Philadelphie, American Philosophical Society, 2007, XIX + 272 p. et 8 pl. — trad. de W. E. Higgins et preface de G. W. Bowersock).

Les Séleucides et les Ptolémées. L'héritage monétaire et financier d'Alexandre le Grand, Monaco, Éditions du Rocher, 2006, 297 p. (avec F. de Callataÿ). 